Ärztliche Erfahrung beschränkt sich nicht auf medizinisches Fachwissen.

\title{
Die blinde Jagd nach Bonuspunkten
}

\begin{abstract}
- Man kann über die Bonusprogramme der Krankenkassen denken, wie man will - es lässt sich aber nicht bestreiten, dass sie manchen Patienten zu mehr Gesundheitsbewusstsein verhelfen. Neulich hatte ich einen jungen Mann in der Praxis, der es ein bisschen übertrieben hat. Sein Problem war, dass er einen normalen Blutdruck in sein Bonusheft eintragen wollte, die Werte aber bei den Messungen in anderen Arztpraxen stets zwischen 140/90 und 150/95 gelegen hat-
\end{abstract}

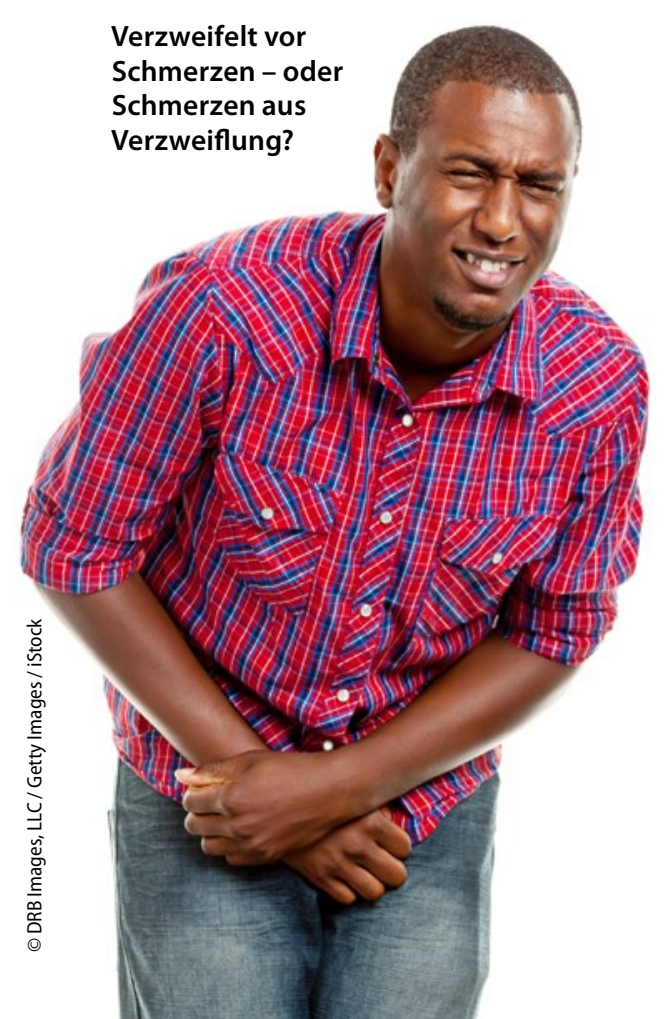

ten - viel zu hoch für sein Alter. Nun wollte er den Bluthochdruck bei mir abklären lassen.

So, wie er wirkte, vermutete ich am ehesten eine Weißkittelhypertonie. Ich schlug zur Verifizierung eine Langzeitmessung vor, was er dankend annahm. Vorher schnappte ich mir aber noch Stethoskop und RR-Manschette, um auch in unserer Praxis einen Gelegenheitswert dokumentieren zu können. Der war allerdings mit 125/85 normal.
Sofort zückte der Patient sein Bonusheft und wollte eine Unterschrift. Meine Weigerung mit der Begründung, dass ich ihm nicht gleichzeitig einen normalen Blutdruck bescheinigen und aufgrund erhöhter Werte weitere Untersuchungen veranlassen könne, konnte er nicht nachvollziehen. Angesichts der vollen Sprechstunde verzichtete ich darauf, ihm Sinn und Zweck des Bonuspunkteprogramms zu erklären.

Dr. Andrea Linsel, Lüneburg

\section{Diagnose: Abschiebebauch}

_ An einem schönen Sonntag wurde ich gebeten, einen Patienten zu untersuchen, der abgeschoben werden sollte. Ich fand den etwa 35-jährigen Schwarzafrikaner auf dem Boden liegend vor, wo er sich unter lautem Wehklagen hin und her drehte. Auf meine anamnestischen Fragen ging er kaum ein, nur die Fragen nach Hepatitis und HIV-Infektion bejahte er. Bei Berührung des stark angespannten Bauchs stieß er laute Schmerzensschreie aus.

Der Allgemeinzustand hingegen schien gut zu sein. Der Patient schwitzte nicht, hatte einen regelmäßigen, normofrequenten Puls und eine gute Pulsfüllung. Alle weiteren erhebbaren Befunde waren unauffällig. Das Gesamtbild passte nicht zu einem akuten Abdomen. Der Verdacht auf Simulation zur
Verhinderung einer Abschiebung drängte sich mir auf. Trotzdem schickte ich den laut schreienden Patienten, der in Polizeibegleitung war, zur Abklärung in die nächste Klinikambulanz.

Am nächsten Abend wurde er mir noch einmal zur Abklärung von Reisefähigkeit vorgestellt, da der Klinikarzt dies vergessen hatte. Der Patient war acht Stunden lang untersucht worden, inklusive fachärztlicher Diagnostik, großem Labor, EKG, Sonografie etc. Sogar ein CT des Abdomens war angefertigt worden. Alles ohne pathologischen Befund.

Heute gab der Patient nur noch einen leichten abdominellen Druckschmerz an. Er schrie und heulte nicht mehr. Er hatte aufgegeben.

Dr. Rainer Hakimi, Stuttgart 